\title{
Structural behavior of non-symmetrical steel cable-stayed bridges
}

\author{
Juan J. Jorquera-Lucerga ${ }^{* 1}$, Jose A. Lozano-Galant ${ }^{2}$ and Jose Turmo ${ }^{3}$ \\ ${ }^{1}$ Department of Civil Engineering, Polytechnic University of Cartagena, \\ Paseo Alfonso XIII 52, 30203, Cartagena, Spain \\ ${ }^{2}$ Department of Civil Engineering, University of Castilla-La Mancha, \\ Av. Camilo Jose Cela SN 13071, Ciudad Real, Spain \\ ${ }^{3}$ Department of Civil and Environmental Engineering, Universitat Politècnica de Catalunya, \\ BarcelonaTech, C/Jordi Girona 1-3, Edif B1, 08034 Barcelona, Spain
}

(Received April 22, 2015, Revised July 14, 2015, Accepted October 20, 2015)

\begin{abstract}
Despite of the growing number of built examples, the analysis of non-symmetrical cable-stayed bridges has not received considerable attention from the researchers. In fact, the effects of the main design parameters in the structural behavior of these bridges are not addressed in detail in the literature. To fill this gap, this paper studies the structural response of a number of non-symmetrical cable-stayed bridges. With this aim, a parametric analysis is performed to evaluate the effect of each of the main design parameters (the ratio between the main and the back span length, the pylon, the deck and backstay stiffnesses, the pylon inclination, and the stay configuration) of this kind of bridges. Furthermore, the role of the geometrical nonlinearity and the steel consumption in stays are evaluated.
\end{abstract}

Keywords: non-symmetrical cable-stayed bridges; parametric study; design parameters; steel bridge; design guidelines

\section{Introduction}

The rapid bloom of cable-stayed bridges has been propitiated by the development of erection techniques and improvements of construction materials (Svensson 2012). According to many authors (see Agrawal 1997), this bridge type is the most economical one for bridge spans ranging between 150 and $360 \mathrm{~m}$. A major concern in the structural efficiency of a cable-stayed bridge and, therefore, in its cost, lies in the symmetry of its longitudinal configuration, i.e., when the side span is roughly the $40 \%$ of the main span for a three span bridge. For this reason, structurally speaking, designers prefer symmetric designs rather than non-symmetric ones, which are limited to those cases where the symmetric solution is discouraged for site conditions. Nevertheless, economic boom of the last decade has deflected attention from economic cost to iconic aesthetical appearance increasing significantly designer's freedom (Jorquera-Lucerga 2013). This structural freedom has enabled the proliferation of a number of non-symmetric cable-stayed bridges that might even go without basic structural elements such as backstays (as the Alamillo Bridge in Spain, Casas and Aparicio 1998).

*Corresponding author, Ph.D., E-mail: juanjo.jorquera@upct.es 
In cable-stayed bridges, all the resistant mechanisms are related, to a greater or lesser extent, to the tensile forces of the stay cables in service. Since current cable-stayed bridges include a highly indeterminate structural system, no unique solution for pre-tensioning stay cable forces exists (Marchetti and Lecinq 1999). In fact, these represent a design parameter that can be tailored to achieve an effective design for the bridge (such as full use of material strength, achievement of target geometry or minimization of structural cost).

The stay cable forces are usually defined to achieve a certain designer's criterion in service, in a stage known as the Objective Service Stage or OSS (see Lozano-Galant et al. 2012a, b). The criteria proposed in the literature to estimate the stay forces in the OSS are reviewed by many authors (see Guan 2000, Chen et al. 2000, Hassan et al. 2012, Lozano-Galant et al. 2013). According to them, some of the most important criteria are as follows: (1) The Pendulus Rule (see Virlogeux 1994, SETRA 2001). This is a simplified method to carry out a first approximation of the stay cable forces in nearly horizontal decks. This criterion assumes that the tension of each stay cable is close to the tension obtained when the deck is hinged at each stay anchorage. In this way, the cable forces can be estimated as the projection in the stay direction of the averaged load introduced into the two adjacent deck segments. (2) Minimization of the Creep Effect Criterion (see Scotti 2003). This criterion defines the stay cable forces in the OSS to minimize the creep effect in concrete structures with vertical stay cables. In order to analyze the creep effects, this method applies the age-adjusted effective modulus method (Bazant 1972). The calculation of the stay forces is performed by solving a system of equations that relates the deflections of the deck when unitary forces are applied into the stay cables and when the permanent load is applied into the structure. (3) Minimal Bending Energy Criterion (Du 1989). This criterion is based on the minimization of the bending energy of the structure. Additionally, this criterion can be used to minimize the effects of the time-dependent phenomena Lozano-Galant and Turmo (2014) and the staggered erection of the superstructure Lozano-Galant et al. (2014, 2015). (4) Rigidly Supported Continuous Beam Criterion (Manterola et al. 2006, Chen et al. 2000, Gimsing 1997). This criterion assumes that the long-term behavior of a cable-stayed bridge corresponds with that of a fictitious rigidly continuous beam. This beam is defined by removing the stay cables and adding fictitious bearings at the bridge deck anchorages. In this way, the stay cable forces can be obtained by projecting the vertical reactions of the corresponding fictitious supports into the stay cable direction. (5) Zero Displacement Criterion (Lazar et al. 1972, Wang et al. 1993). This criterion defines the stay cable forces to achieve zero deflections at certain control points of the structure. A common criterion consists of defining zero vertical deflection at the deck-stay connection and zero horizontal deflection at the top of the pylon in structures with backstays. To achieve this goal (Wang et al. 1993) proposed the use of an iterative process in which the prestressing stay cable forces are successively updated to minimize the deflections at the control points. Some other methods, such as the B-spline curve criterion (Hassam et al. 2012, Hassam 2013), are also based, to a great extent, on the analysis of the bridge deflections. The Minimization of the Sum of Squares Method criterion defines the stay cable forces by an optimization analysis in which the sum of the squares of the vertical deflections along the bridge deck is minimized. On the other hand, the B-spline curves criterion proposes the optimization, by mean of genetic algorithms, of the post-tensioning functions to achieve minimum deck deflections. These post-tensioning functions are defined by B-spline curves. (6) The Unit Load Method (Janjic et al. 2002, 2003). This criterion is based on a linear system of equations that includes a degree of freedom for each stay cable force. This system relates the bending moments at some control points for two types of load cases: unitary prestressing loads at each stay cable and the target load of the superstructure. 
This system of equations can be directly solved by mean of an influence matrix after defining the desired stress distribution moment distribution to be achieved. A similar approach was used by Guan in terms of deflections. (7) Optimization Criterion (Baldomir et al. 2010, Negrao and Simoes 1997, Simoes and Negrao 2000). In this criterion, the prestressing stay cable forces are defined by the minimization of a scalar objective function. Different tendencies are used to define these objective functions. Some designers base their objective functions on the structural efficiency while some others base it on the economy of the structure. To reduce the computation time of the optimization process, Lute et al. (2009) proposed the use of genetic algorithms.

All criteria presented above might be applied to symmetric cable-stayed structures. Nevertheless, not all of them are adequate to non-symmetric ones. This is the case of the Pendulus rule and the Rigidly Continuous Beam Criterion as they provide no information of the backstay forces. For this reason, sometimes the designers have to look for alternative methods. This was the case of the design of the Alamillo Bridge (Casas and Aparicio 1998). In this structure the stay cables forces in the main span were defined to correspond with those of an equivalent continuous beam. Nevertheless, the weight of the inclined pylon was defined to assure that the resultant of the stay forces remained inside the pylon. The lack of studies referring to non-symmetrical cablestayed bridges is not limited to the backstay forces as the effects of the main design parameters (such as the ratio between the main and the back span length, the pylon and the deck stiffnesses, the pylon inclination or the stay configuration) are not conveniently addressed either.

To fill the detected gaps, this paper studies the structural behavior of highly non-symmetrical two span cable-stayed bridges made of steel. With this aim, a number of parametric analyses focused on each of the main design parameters (ratio between the main and the back span length, the pylon and the deck stiffnesses, the pylon inclination of the stay configuration) are presented. Furthermore, the effect of the geometrical nonlinearity in these structures is proved to be not significant.

This paper is organized as follows: In Section 2, the layout and the load cases in the case of study are presented. In Section 3, the calculation and the assumptions of the study are presented. In Section 4, the results of the parametric analyses are discussed. Finally, a set of conclusions are drawn in Section 5.

\section{Cases of study}

The cases of study consist of a cable-stayed bridge whose geometry is modified to analyze the effects of different non-symmetrical configurations. In this section, the configurations and load cases of the analyzed non-symmetric bridges are presented.

\subsection{Configurations}

The main parameters that define the geometry of a two span non-symmetric cable-stayed bridge may be defined as follows: (1) Back span, $L_{1}$, (2) Main span, $L_{2}$, (3) Pylon height over the deck, $H_{1}$, (4) Pylon height below the deck, $H_{2}$, (5) Pylon inclination, $\alpha$, (6) Backstay inclination, $\alpha_{1}$, (7) Lower main span stay inclination, $\alpha_{2}$, (8) Cable arrangement, in which the stay cables are distributed throughout the pylon. The studied arrangements are Harp (parallel cables) and SemiFan (cables distributed throughout a certain length $h$, near the top of the pylon), (9) Anchorage separation in the pylon back span, $h_{1},(10)$ Anchorage separation in the pylon main span, $h_{2},(11)$ Number of stay cables in the back span, $n_{1}$, (12) Number of stay cables in the main span, $n_{2},(13)$ 


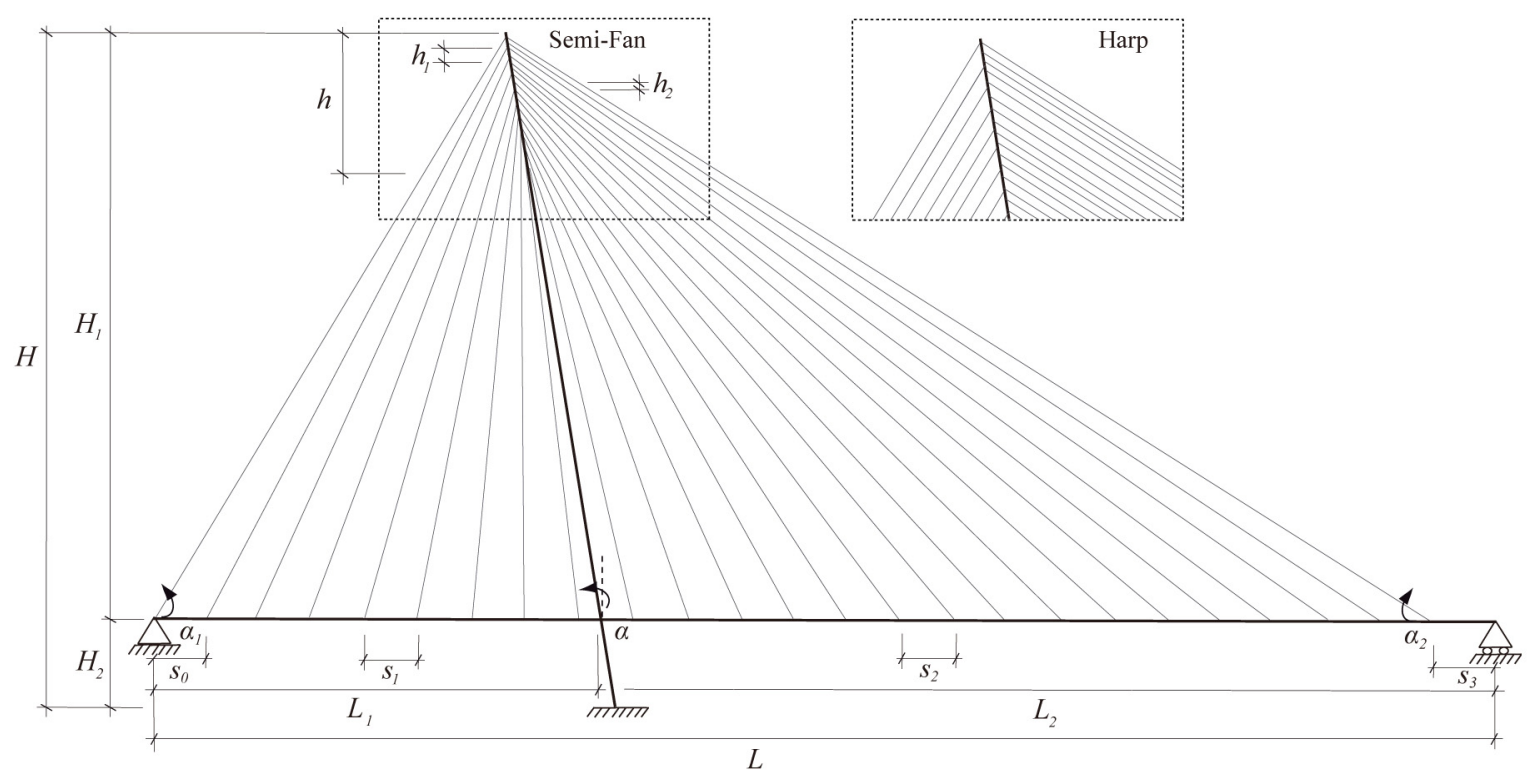

Fig. 1 Main parameters of a non-symmetrical cable-stayed bridge with different stay configurations

Separation of the backstay, $s_{0}$, (14) Anchorage separation in the deck back span, $s_{1},(15)$ Anchorage separation in the deck main span, $s_{2}$. (16) Separation of the deck last stay, $s_{3}$. All these parameters are summarized in Fig. 1.

The assumptions considered in this study might be summarized as follows: (1) Pylon-deck connection: As considered in many of actual bridges, a configuration pioneered by Severins Bridge (1960) over the River Rhine in Cologne: see e.g., Zárate-Brazo Largo cable-stayed bridge (Svensson 2012) no pylon-deck connection is considered. (2) Valid range of stay inclinations: To assure an adequate efficiency of the backstays, $\alpha_{1}$ and $\alpha_{2}$ must remain into a certain range of validity. In this study, this range has been assumed between $30^{\circ}$ and $60^{\circ}$, although smaller values outside this range could also be considered (e.g., Menn (1990) considered minimum stay inclinations of $22^{\circ}$ ). (3) Fixed parameters in non-symmetrical configurations: To homogenize the characteristics of the analyzed bridges, all the examples share the following fixed parameters $L_{2}=$ $100 \mathrm{~m}, s_{0}=s_{1}=s_{2}=6 \mathrm{~m}, s_{3}=7 \mathrm{~m}, H_{2}=15 \mathrm{~m}$ and $n_{2}=15$. (4) Parameters defining the nonsymmetrical configuration: The non-symmetrical configurations are defined in terms of the fixed parameters and fixing $\alpha, \alpha_{1}$ and $h$. Firstly, the pylon top can be obtained by intersecting the last main span stay and the pylon. In this way, $H_{2}$ can be calculated in terms of $\alpha_{1}$ and $\alpha$ as presented in Eq. (1). This height can be used to calculate $L_{1}$ as presented in Eq. (2). In order to satisfy $s_{0}=6 \mathrm{~m}$ and $S_{1}=6 \mathrm{~m}$ with an integer number of stay cables, the admissible $L_{1}$ are restricted to $10 \mathrm{~m}, 21 \mathrm{~m}$, $33 \mathrm{~m}, 51 \mathrm{~m}, 63 \mathrm{~m}, 75 \mathrm{~m}, 81 \mathrm{~m}$ and $99 \mathrm{~m}$. For each of these values of $L_{1}, n_{1}$ can be estimated from Eq. (3). Finally, $h_{1}$ can be obtained in terms of $h$ and $n_{1}$ as presented in Eq. (4). The calculation of $h_{2}$ can be carried out by substituting $n_{1}$ to $n_{2}$ in Eq. (4). (5) The effects of the staggered erection of the superstructure are neglected. (6) Steel relaxation is neglected. The simulation of this phenomena can be found in Gunaydin et al. (2014) and Atmaca and Ates (2012).

$$
H_{2}=\frac{\tan \left(\alpha_{1}\right) \cdot L_{2}}{1-\tan (\alpha) \cdot \tan \left(\alpha_{1}\right)}
$$




$$
\begin{gathered}
L_{1}=H_{2}\left(\tan (\alpha)+\frac{1}{\tan \left(\alpha_{1}\right)}\right)<L_{2} \\
N_{2}=\left(\frac{L-S_{3}}{S_{1}}\right)+1-N_{1} \\
h_{1}=\left(\frac{h}{N_{1}}\right)
\end{gathered}
$$

The valid cases that satisfy stay cables efficiency condition for $L_{1}=100 \mathrm{~m}$ are located into the shadowed region of Fig. 2(A) in terms of $L_{1}, \alpha$ and $\alpha_{1}$. To reduce the number of bridge geometries available for the parametric analysis only some $\alpha\left(-20^{\circ},-10^{\circ}, 0^{\circ}, 10^{\circ}\right.$ and $\left.20^{\circ}\right)$ are studied, where
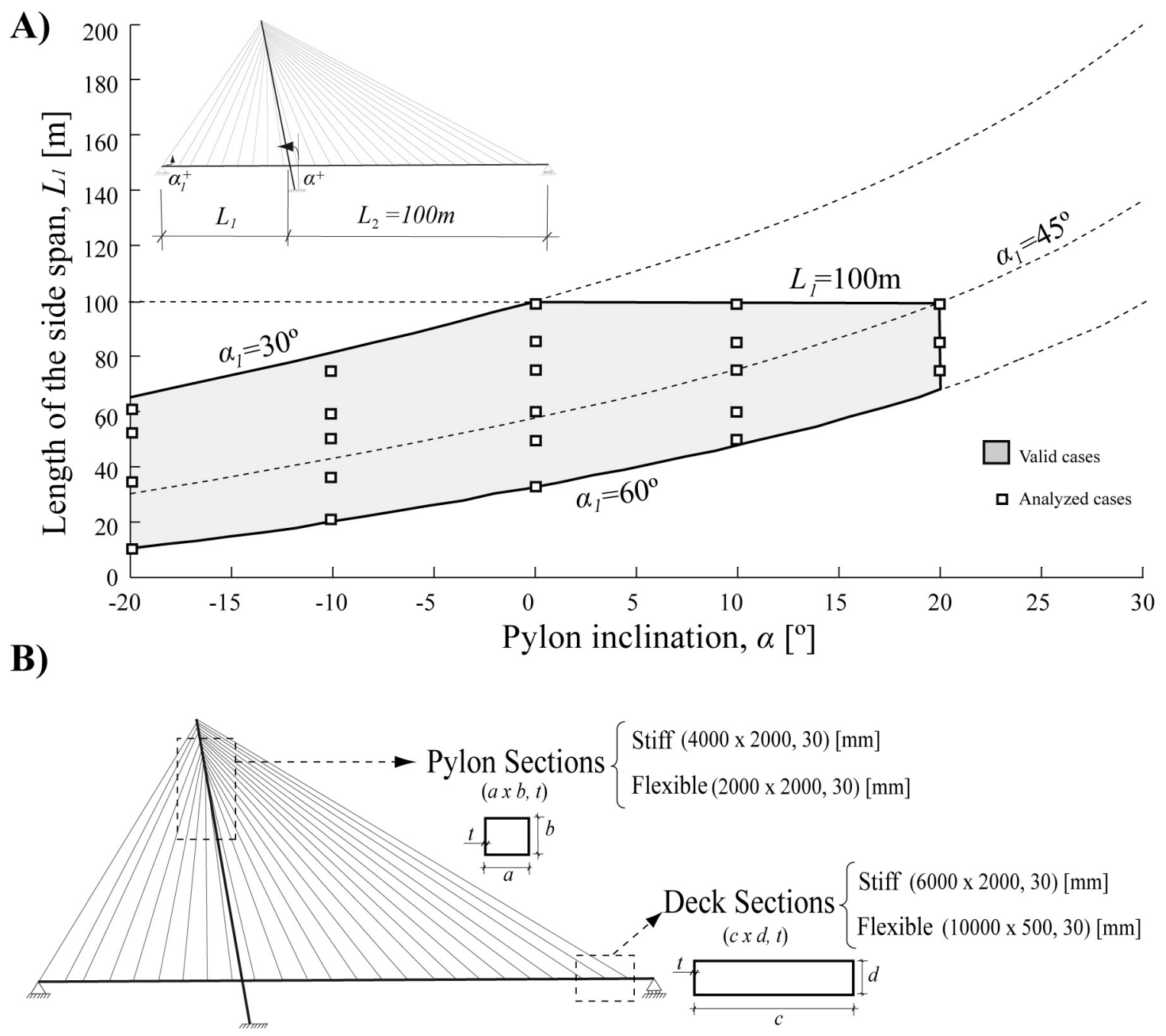

Fig. 2 Cases analyzed in the parametric study. (a) Valid and analyzed cases in the parametric study; and (b) Analyzed pylon and deck cross-sections 
Table 1 Mechanical properties of the structural elements

\begin{tabular}{cccc}
\hline \hline & Area $\left(\mathrm{m}^{2}\right)$ & Inertia $\left(\mathrm{m}^{4}\right)$ & $E(\mathrm{GPa})$ \\
\hline Flexible pylon & 0,236 & 0,153 & 210 \\
Stiff pylon & 0,356 & 0,779 & 210 \\
Flexible deck & 0,476 & 0,034 & 210 \\
Stiff deck & 0,626 & 0,386 & 210 \\
Stay & $*$ & 0,000 & 195 \\
\hline
\end{tabular}

* The stay areas are defined for each model

a negative angle represents a pylon leaning backwards and a positive angle represents a pylon leaning forward the main span. The agreement between the studied $\alpha$ and the admissible $L_{1}$ results in the 23 analyzed cases summarized in Fig. 2(A). Each of these geometries is analyzed with the two alternative pylon and deck sections presented in Fig. 2(B). Differences between both sections (Stiff and Flexible) refer to their stiffness. The sections stiff and flexible sections in the steel pylon are $4000 \times 2000$ and $2000 \times 2000 \mathrm{~mm}$ with $30 \mathrm{~mm}$ thickness, respectively. In the case of the deck, the stiff and Flexible sections are $6000 \times 2000$ and $10000 \times 500 \mathrm{~mm}$ with $30 \mathrm{~mm}$ thickness. It is remarked that all analyzed pylons and decks are assumed to be made of steel. Therefore, timedependent phenomena that occur in concrete bridges are not considered. The mechanical properties of both the deck and the pylon are summarized in Table 1. The steel Young's modulus is $210000 \mathrm{MPa}$ for the deck and the pylon and $195000 \mathrm{MPa}$ for the stay cables. The ultimate stay strength, $f_{\text {GUTS }}$, is $1860 \mathrm{MPa}$. These values are obtained from (Eurocode 2005). The areas of the stay cables are not included in this table as they are calculated for each cable in each model.

The configurations of the studied examples vary to analyze the influence of the following variables: (1) Pylon inclination $\alpha$ (ranging from $-20^{\circ}$ to $20^{\circ}$ ); (2) Deck cross section (Stiff or Flexible in Fig. 2(B)); (3) Pylon cross section (Stiff or Flexible in Fig. 2(B)); and (4) Stay cable configuration (Semi-Fan or Harp in Fig. 1(A)). In addition to these analyses, a study of the effects of the geometrical nonlinearity is presented. All these variations results in a number of 368 analyzed structures.

\subsection{Analyzed load cases}

The analyzed load cases include: (1) Permanent loads. These loads include the self-weight and a superimposed dead load of $3 \mathrm{kN} / \mathrm{m}^{2}$, that is to say $30 \mathrm{kN} / \mathrm{m}$ for a $10 \mathrm{~m}$ wide deck. (2) Live loads. The load LM4 $\left(5 \mathrm{kN} / \mathrm{m}^{2}\right)$ of the European Code- 1 , that is $50 \mathrm{kN} / \mathrm{m}$, is considered.

\section{Calculation and assumptions}

In this section after summarizing the calculation procedure, the main simulation assumptions are presented.

\subsection{Calculations}

In the parametric analysis, the service behavior of a number of non-symmetric cable-stayed bridges is analyzed with SAP2000. These structures are simulated by Finite Element Models $(F E M s)$. These FEMs simulate each deck and pylon segment between stay anchorages by mean of 


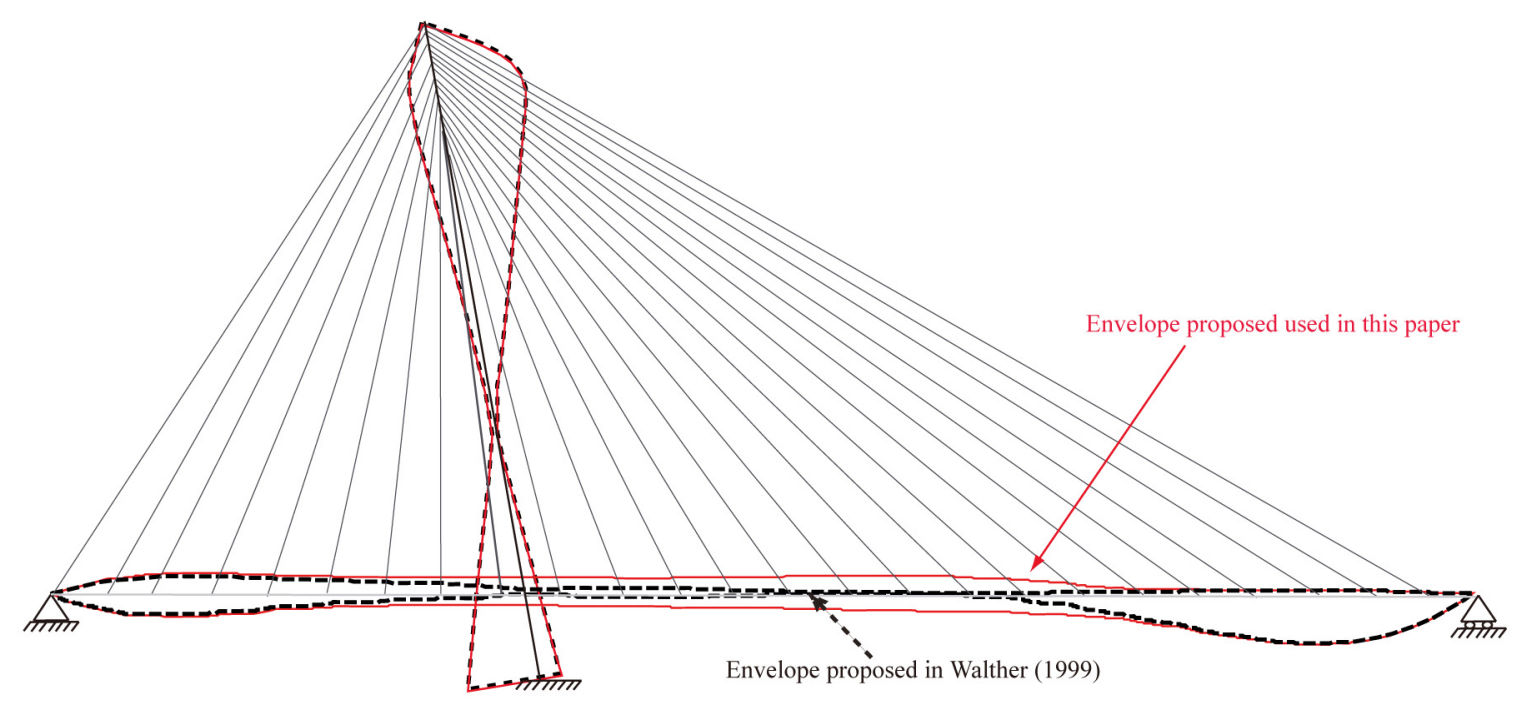

Fig. 3 Envelope of bending moments in service. The envelope proposed in Walther et al. (1999) is presented by a dotted line and the one used in this paper by a continuous one

a different beam element with six degrees of freedom. The stay cables are simulated by beam elements pinned at both edges.

Some authors recommend the calculation of the stress envelopes in cable-stayed bridges by analyzing a limited number of load cases. This is the case of Walther et al. (1999), who only considers two load cases to study the live load effects. These load cases correspond with placing the live load either in the main span or in the back span. Using this limited number of load cases provides accurate prediction of the maximum stresses in deck and pylon. Nevertheless, the obtained stresses at the inner part of the deck remain on the non-conservative side. To illustrate this, Fig. 3 is analyzed. This figure compares the Walther's bending moment envelope, in blue solid dash, with the bending moment envelope obtained when every live load location is considered, in red solid dash. This figure shows that both envelopes present the same stresses in the pylon and in the proximities of the deck abutments (where the maximum deck bending moments are found). Nevertheless, this is not the case at the inner part of the deck where the accuracy of the Walther's envelope is lost (as higher bending moments are obtained by the red envelope). In view of these results, and to assure an accurate simulation of the whole bridge, the stress and deflection envelopes calculated in this paper have been obtained considering all possible live load locations. To do so, the analyzed FEMs include a number of load cases equal to the number of deck beam elements.

\subsection{Assumptions}

The analyses carried out are based on the following assumptions:

(1) Geometry of the FEMS and load cases. The geometry of the FEMs and the load cases analyzed are presented in Section 2.1 and 2.2, respectively.

(2) Definition of all stay cable cross sections but the backstay one. The stay cable cross sections must fulfill two criteria simultaneously. The first one is the limitation of the 
maximum stresses. To prevent fatigue failure, the stay cables are designed to avoid exceeding the $45 \%$ of the ultimate stay strength, $f_{G U T S}$ under the characteristic combination (see SETRA 2001). The second one is the limitation of increment of stresses. To prevent fatigue failure, the maximum increment of stress in stay cables due to live loads, $\Delta \sigma_{\max }$, must be controlled. In this paper, this value has been fixed to $200 \mathrm{MPa}$. The amount of live loads that must be considered for fatigue checking are specified in codes. In this paper, the fatigue load considered is equal to the $100 \%$ of the characteristic live load. The area of every stay cable, $A_{c}$, can be expressed as

$$
A_{c}=\max \left(\frac{(P L+L L) \cdot s}{\sin (\alpha) \cdot 0.45 \cdot f_{G U T S}}, \frac{L L \cdot s}{\sin (\alpha) \cdot \Delta \sigma_{\max }}\right)
$$

where $P L$ and $L L$ are the Permanent and Live loads, $s$ is the cable spacing and $\alpha$ is the cable inclination defined in Fig. 1. This procedure is based on the method of the tributary area proposed by Svensson (2012).

(3) Definition of stay cable forces in all stays but the backstays due to permanent loads. According to Svensson (2012), the Rigidly Supported Continuous Beam Criterion has been used to define the axial load of the stay cables due to permanent loads.

(4) Definition of backstay area and force due to permanent loads. The definition of the area and force of the backstay is not as straightforward as in the case of the rest of the stay cables. The difficulty in defining these elements comes from the fact that backstay force and stiffness are strongly linked with both bridge forces and deflections. This problem has to be solved by an iterative process, in which each iteration represents a different FEM of the whole bridge with a certain backstay area. In this model, the axial force of the backstay is defined to set the bending moment at the bottom of the pylon to zero when the permanent loads and the axial forces in the rest of stays calculated according to the preceding paragraph are applied. Once defined the axial force of the backstay for permanent loads, the variation of stresses, $\Delta \sigma_{\max }$, and the maximum tensile stresses in the backstay are calculated using a FEM model. If any of these values exceeds the design thresholds, a new area of the backstay is defined. This new area is introduced in the FEM that is used in the following iteration.

\section{Parametric studies, results and discussion}

This section studies the effects of the main design parameters of the non-symmetrical cablestayed bridges in the structural behavior of their structural elements (stays, pylon and deck). The analyzed design parameters are: the back span length, the pylon inclination, the pylon stiffness, the deck stiffness, the backstay stiffness, the stay arrangement and the geometrical nonlinearity, After presenting the results of these analyses, they are discussed in detail.

\subsection{Parametric studies}

In this section, the results of the analyzed design parameters are presented. It is remarked that the geometry and the stay areas of all the proposed models are defined according to the procedures described in Sections 1 and 3, respectively. The Stiff and Flexible sections for the pylon and deck are described in Fig. 2. 


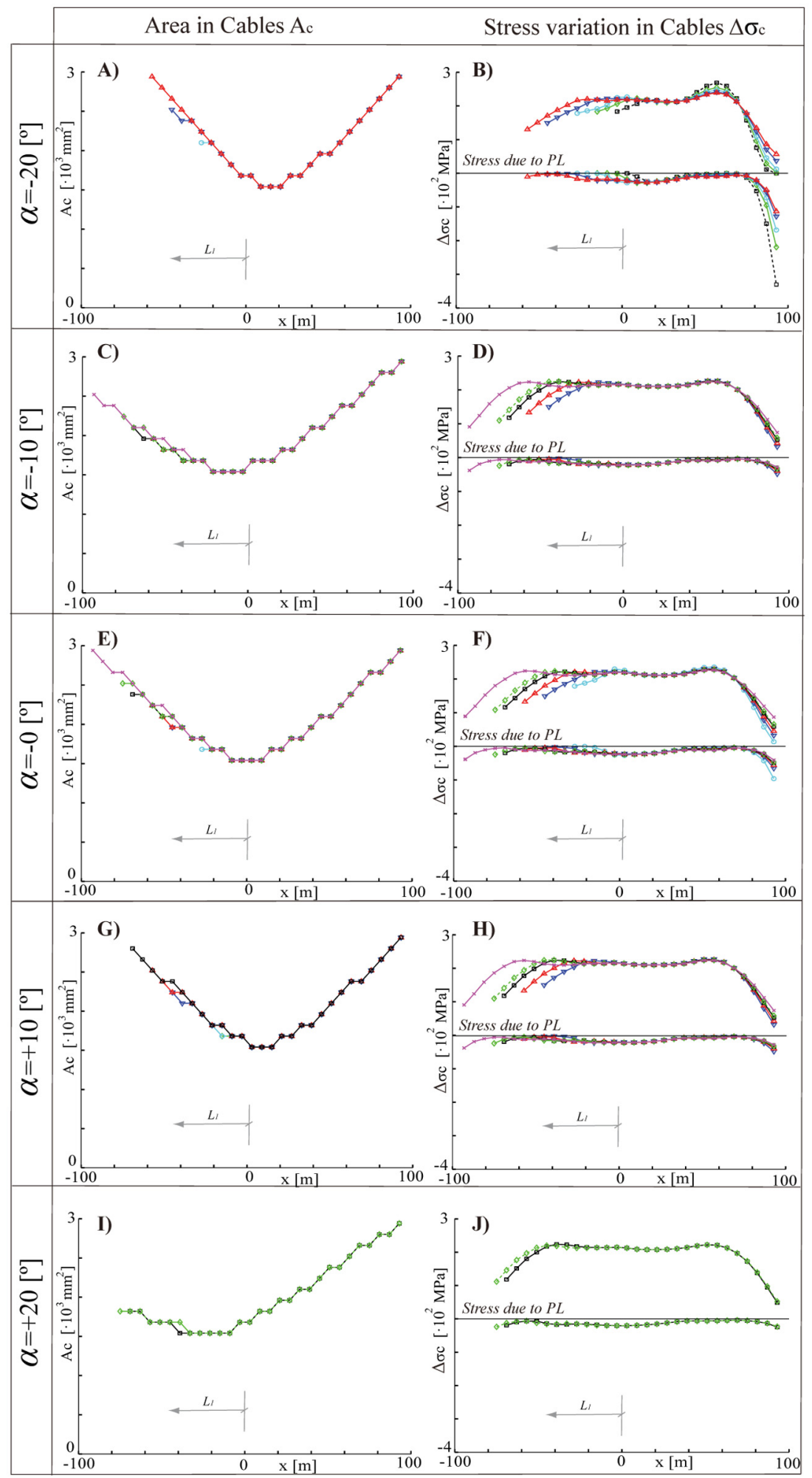

Fig. 4 Definition of the models 

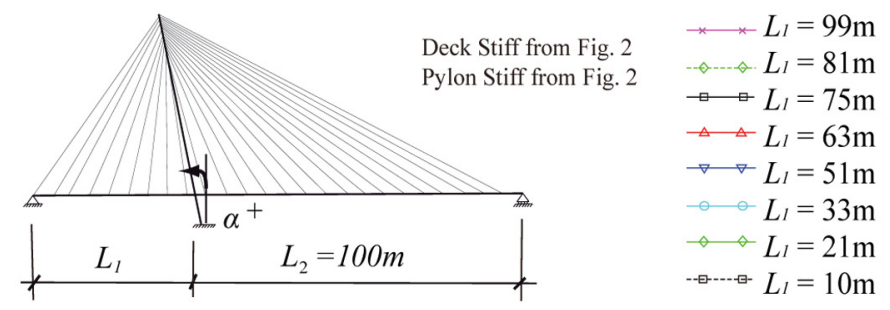

Fig. 4 Continued

\subsubsection{Study of the backspan length, $L_{1}$}

This section studies the effect of the back span length, $L_{1}$, on non-symmetrical cable-stayed bridges with five different pylon inclinations $\left(\alpha=-20^{\circ},-10^{\circ}, 0^{\circ}, 10^{\circ}\right.$ and $\left.20^{\circ}\right)$. The analyzed back span lengths are: (1) $\alpha=-20^{\circ}: 5$ models ( $L_{1}=10 \mathrm{~m}, 21 \mathrm{~m}, 33 \mathrm{~m}, 51 \mathrm{~m}$ and $63 \mathrm{~m}$ ). (2) $\alpha=-10^{\circ}: 5$ models $\left(L_{1}=21 \mathrm{~m}, 33 \mathrm{~m}, 51 \mathrm{~m}, 63 \mathrm{~m}\right.$ and $\left.75 \mathrm{~m}\right)$. (3) $\alpha=0^{\circ}: 6$ models $\left(L_{1}=33 \mathrm{~m}, 51 \mathrm{~m}, 63 \mathrm{~m}, 75\right.$ $\mathrm{m}, 81 \mathrm{~m}$ and $99 \mathrm{~m})$. (4) $\alpha=+10^{\circ}: 5$ models $\left(L_{1}=51 \mathrm{~m}, 63 \mathrm{~m}, 75 \mathrm{~m}, 81 \mathrm{~m}\right.$ and $\left.99 \mathrm{~m}\right)$. (5) $\alpha=$ $+20^{\circ}: 2$ models $\left(L_{1}=75 \mathrm{~m}\right.$ and $\left.81 \mathrm{~m}\right)$. The area of the cables, $A_{c}$, assuming stiff sections in both the deck and the pylon are presented in Fig. 4(A). The stress variations in cables due to live loads, $\Delta \sigma_{c}$, are presented in Fig. 4(B).

The structural responses in the deck and the pylon of each model are detailed in Fig. 5 on the same scale. This figure includes the envelopes of bending moments in the deck, $M_{D}$ (Fig. 5(A)), the envelopes of vertical deflections in the deck, $v_{D}$, (Fig. 5(B)), the envelopes of bending moments in the pylon, $M_{P}$ (Fig. 5(C)) and the envelopes of horizontal deflection in the pylon, $u_{P}$, (Fig. 5(D)).

\subsubsection{Study of the pylon inclination $\alpha$}

This section analyzes the effect of the pylon inclination, $\alpha$, in non-symmetrical cable-stayed bridges with the same back span length $\left(L_{1}=51 \mathrm{~m}\right)$. The areas of the cable, $A_{c}$, obtained for the five analyzed pylon inclinations $\left(\alpha=-20^{\circ},-10^{\circ}, 0^{\circ}\right.$ and $\left.10^{\circ}\right)$ are summarized in Fig. 6(A).

Fig. 6 also includes the stress variations in cables due to live loads, $\Delta \sigma_{c}$, (Fig. 6(B)), the envelopes of bending moments in the deck, $M_{D}$, (Fig. 6(C)), the envelopes of vertical deflections in the deck, $v_{D}$, (Fig. 6(D)), the envelopes of bending moments in the pylon, $M_{P}$, (Fig. 6(E)), and the envelopes of horizontal deflection in the pylon, $u_{P}$, (Fig. 6(F)).

\subsubsection{Study of the pylon stiffness}

This section studies how the pylon stiffness influences the structural behavior of nonsymmetrical cable-stayed bridges with a vertical pylon $\left(\alpha=0^{\circ}\right)$ and six different back span lengths $\left(L_{1}=33 \mathrm{~m}, 51 \mathrm{~m}, 63 \mathrm{~m}, 75 \mathrm{~m}, 81 \mathrm{~m}\right.$ and $\left.99 \mathrm{~m}\right)$. With this aim, the effects of two different pylon stiffnesses (Stiff and Flexible) are analyzed. The stiffness of the deck is assumed as Flexible.

Fig. 7 summarizes the area of the cables, $A_{c}$, (Fig. 7(A)), the stress variations in cables due to live loads, $\Delta \sigma_{c}$, (Fig. 7(B)), the envelope of bending moments in the deck, $M_{D}$ (Fig. 7(C)), the envelope of vertical deflections in the deck, $v_{D}$, (Fig. 7(D)), the envelope of bending moments in the pylon, $M_{P}$, (Fig. 7(E)), and the envelope of horizontal deflections in the pylon, $u_{P}$, (Fig. 7(F)). In this figure continuous lines indicate the results for the Stiff pylon and the dotted ones the results of the Flexible pylon.

\subsubsection{Study of the deck stiffness}

This section analyzes the effects of the deck stiffness in non-symmetrical cable stayed bridges 
with a vertical pylon $\left(\alpha=0^{\circ}\right)$ and six different back span lengths $\left(L_{1}=33 \mathrm{~m}, 51 \mathrm{~m}, 63 \mathrm{~m}, 75 \mathrm{~m}, 81\right.$ $\mathrm{m}$ and $99 \mathrm{~m}$ ). In this analysis, two different deck stiffnesses (Stiff and Flexible) are considered.

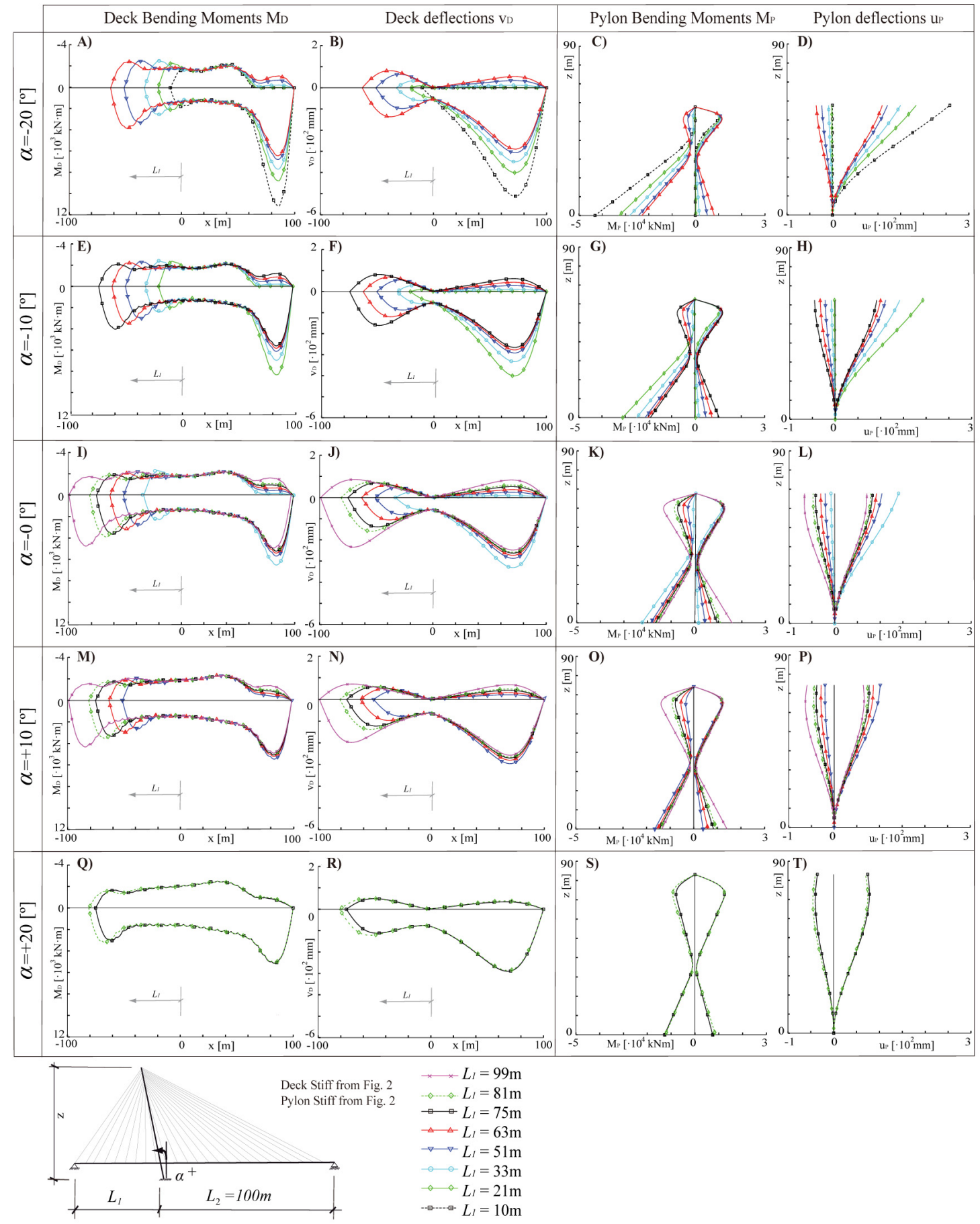

Fig. 5 Study of the back span $L_{1}$ 


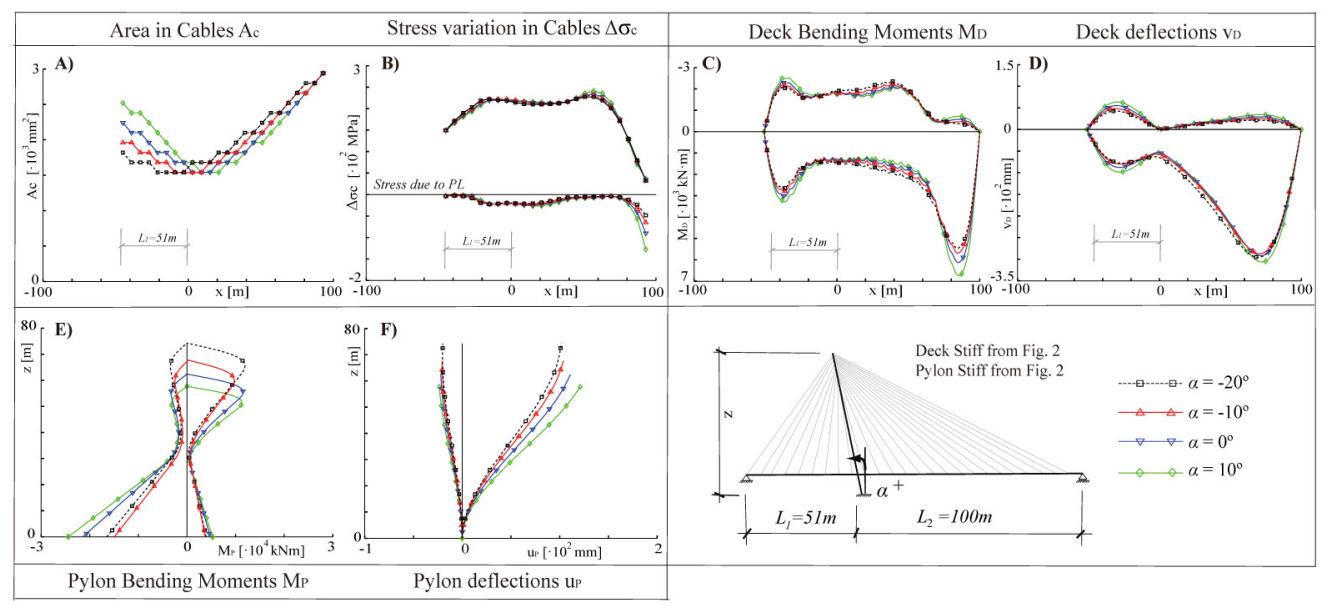

Fig. 6 Study of the pylon inclination $\alpha$ with $L_{1}=51 \mathrm{~m}$

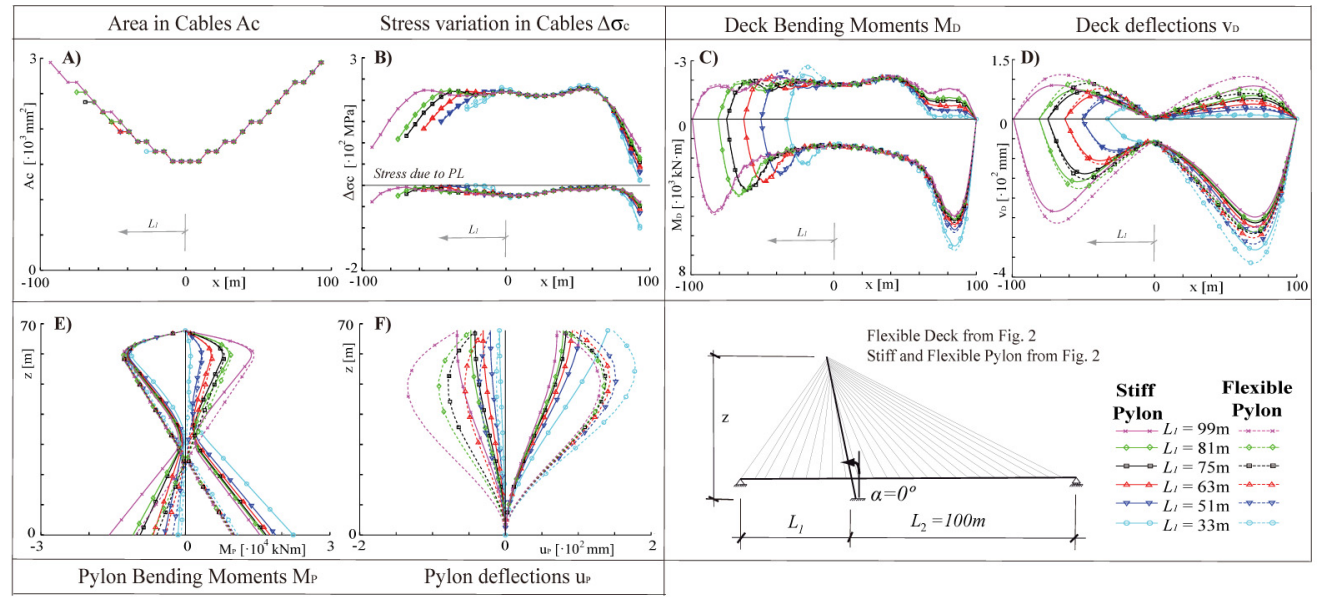

Fig. 7 Study of the pylon stiffness

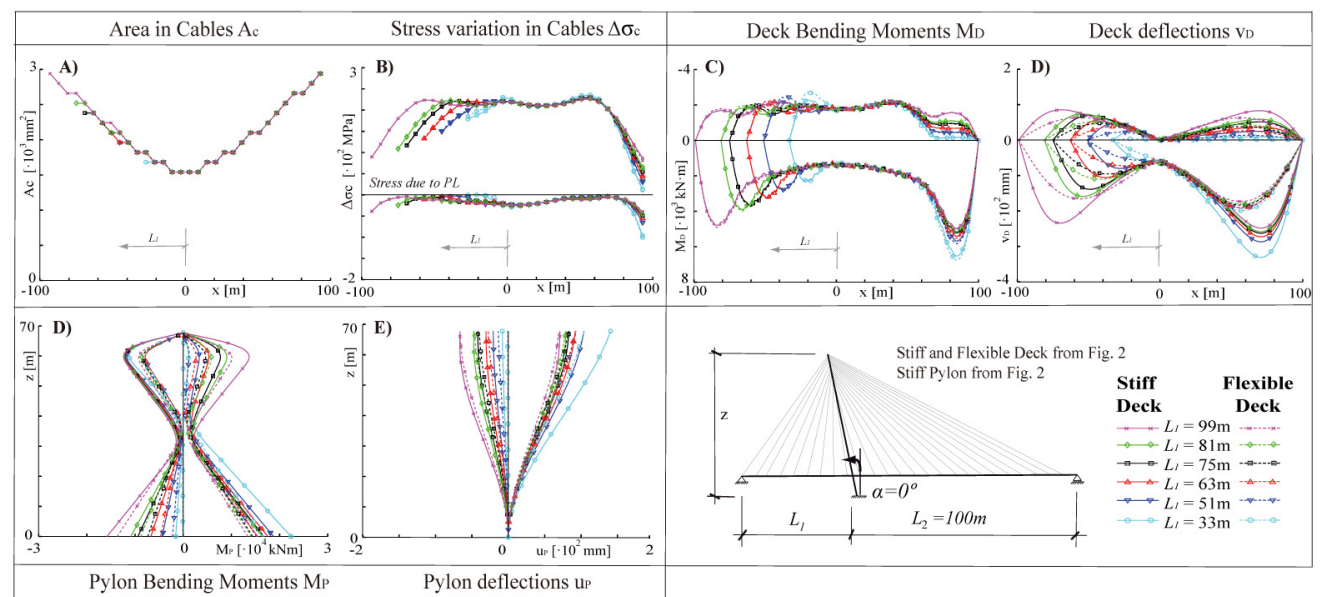

Fig. 8 Study of the deck stiffness 


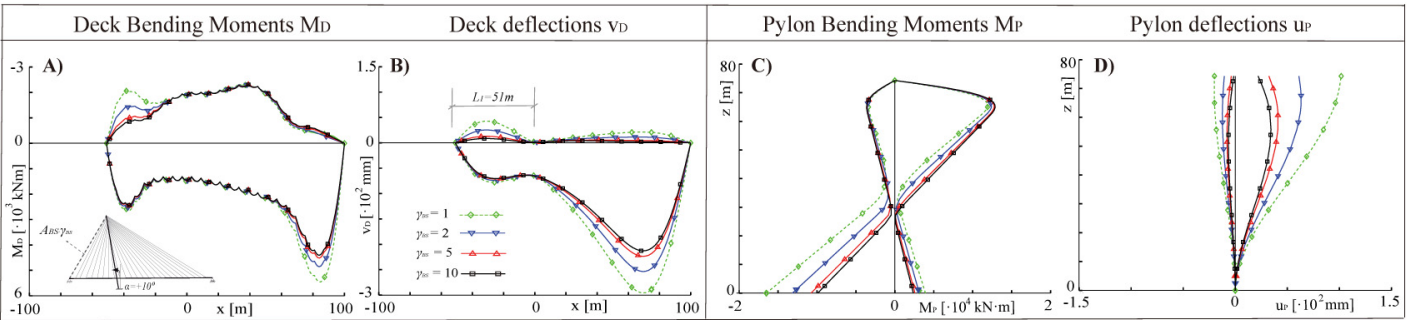

Fig. 9 Study of the backstay stiffness

The stiffness of the pylon is assumed as Stiff.

The results of the parametric analysis are summarized in Fig. 8. This figure includes: the area of the cables, $A_{c}$, (Fig. 8(A)), the stress variations in cables due to live loads, $\Delta \sigma_{c}$, (Fig. 8(B)), the envelope of bending moments in the deck, $M_{D}$, (Fig. $8(\mathrm{C})$ ), the envelope of vertical deflections in the deck, $v_{D}$, (Fig. 8(D)), the envelope of bending moments in the pylon, $M_{P}$, (Fig. 8(E)), and the envelope of horizontal deflections in the pylon, $u_{P}$, (Fig. 8(F)). It is remarked that continuous and dotted lines are used to identify the results of the Stiff and the Flexible deck, respectively.

\subsubsection{Study of the backstay stiffness}

This section studies the effects of the backstay stiffness in non-symmetrical cable stayed bridges with an inclined pylon $\left(\alpha=10^{\circ}\right)$ and a back span length, $L_{1}$, of $51 \mathrm{~m}$. The areas of the stay cables strictly required by the procedure described above, $A_{B S}$, are presented in Fig. 4(A).

With the aim of analyzing the effects of the backstay stiffness, the minimum backstay area, $A_{B s}$, has been factored by $\gamma_{B S}$. Values of $\gamma_{B S}=2,5$ and 10 have been considered and the obtained results are compared with the reference values $\left(\gamma_{B S}=1\right)$ in Fig. 9. This figure summarizes the envelope of bending moments in the deck, $M_{D}$, (Fig. 9(A)), the envelope of vertical deflections in the deck, $v_{D}$, (Fig. 9.B), the envelope of bending moments in the pylon, $M_{P}$, (Fig. 9(C)), and the envelope of horizontal deflections in the pylon, $u_{P}$, (Fig. 9(D)).

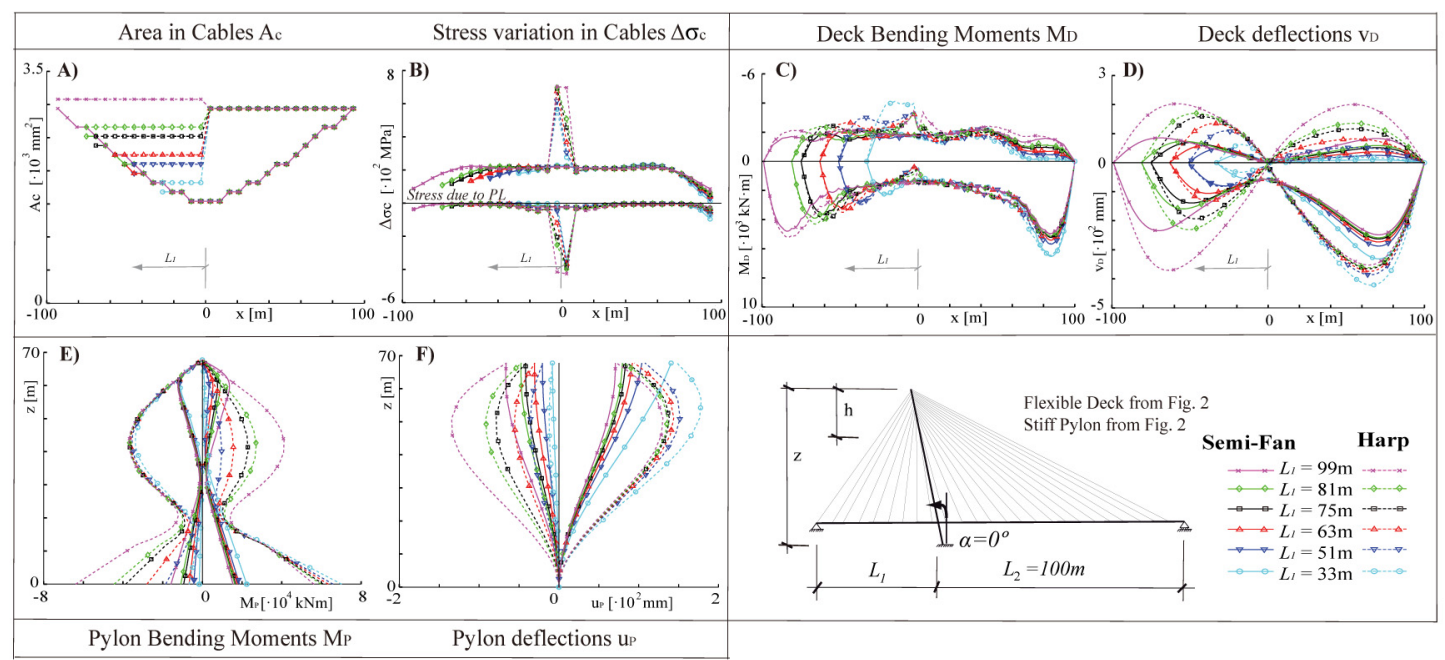

Fig. 10 Study of the stay configuration 


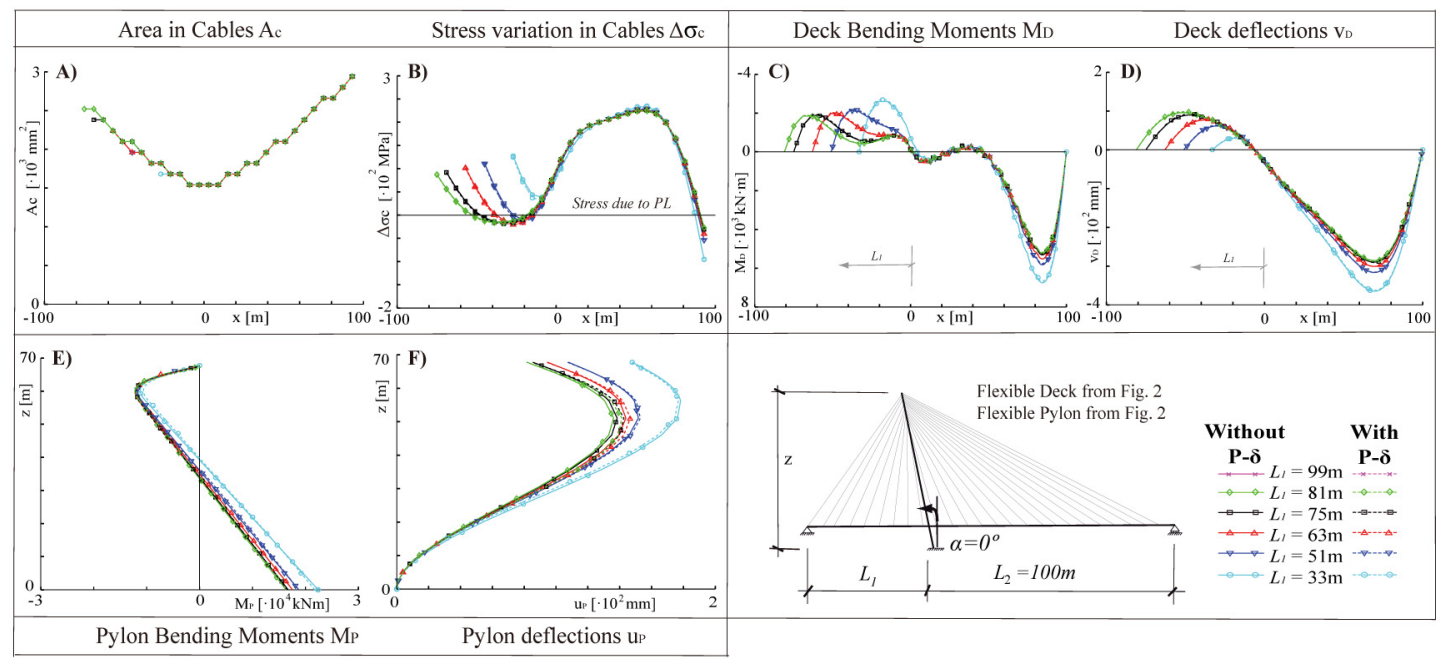

Fig. 11 Study of the geometrical nonlinearity

\subsubsection{Study of the stay configuration}

This section analyzes how the stay configuration (Semi-Fan or Fan in Fig. 1) influences the response of non-symmetrical cable-stayed bridges. The analyzed structures include a vertical pylon $\left(\alpha=0^{\circ}\right)$ and six different back span lengths $\left(L_{1}=33 \mathrm{~m}, 51 \mathrm{~m}, 63 \mathrm{~m}, 75 \mathrm{~m}, 81 \mathrm{~m}\right.$ and $\left.99 \mathrm{~m}\right)$.

The results of the parametric analysis are summarized in Fig. 10. This figure includes: the cable areas, $A_{c}$, (Fig. 10(A)), the stress variations in cables due to live loads, $\Delta \sigma_{c}$, (Fig. 10(B)), the envelope of bending moments in the deck, $M_{D}$, (Fig. 10(C)), the envelope of vertical deflections in the deck, $v_{D}$, (Fig. 10(D)), the envelope of bending moments in the pylon, $M_{P}$, (Fig. 10(E)), and the envelope of horizontal deflections in the pylon, $u_{P}$, (Fig. 10(F)). It is to highlight that continuous and dotted lines are used to identify the results of the Semi-Fan and Harp system, respectively.

\subsubsection{Study of the geometrical nonlinearity}

This section studies the effects of the geometrical nonlinearity $(P-\delta)$ in the non-symmetrical cable-stayed bridges. The analyzed structures include a vertical pylon $\left(\alpha=0^{\circ}\right)$ and six different back span lengths ( $L_{1}=33 \mathrm{~m}, 51 \mathrm{~m}, 63 \mathrm{~m}, 75 \mathrm{~m}, 81 \mathrm{~m}$ and $\left.99 \mathrm{~m}\right)$.

Fig. 11 summarizes the cable areas, $A_{c}$, (Fig. 11(A)), the envelope of increments of axial stresses in the stays, $\Delta \sigma_{c}$, (Fig. 11(B)), the envelope of bending moments in the deck, $M_{D}$, (Fig. 11(C)), the envelope of vertical deflections in the deck, $v_{D}$, (Fig. 11(D)), the envelope of bending moments in the pylon, $M_{P}$, (Fig. 11(E)), and the envelope of horizontal deflections in the pylon, $u_{P}$, (Fig. 11(F)). In this figure, continuous and dotted lines are used to identify the results of the analyses with and without $P$ - $\delta$ effects, respectively.

\subsection{Results}

In this section, the results of the parametric analysis presented in the preceding section are discussed in detail.

\subsubsection{Study of the back span length}

Fig. 4(A) shows that the stay cable areas are not influenced by the back span length, $L_{1}$, since 
these areas only depend on the stay inclination. Obviously, the higher the inclination the lesser efficient the cable and therefore, the higher the area. As illustrated in Fig. 4(B), the back span length does not play an important role in the oscillation of the stay stresses. Nevertheless, this figure shows that $L_{1}$ does influence the maximum and the minimum values, especially in the least efficient stays (e.g., stays located near the abutment of the main span). In this case, the smaller $L_{1}$ is the higher the minimum increments of axial stresses and the lower the maximum ones are. For example, in the models with $\alpha=-20^{\circ}$ the maximum values of the stress oscillations in stays vary from $+0 \mathrm{MPa}$ for $L_{1}=10 \mathrm{~m}$ to $+60 \mathrm{MPa}$ for $L_{1}=99 \mathrm{~m}$. In the case of the minimum values, they vary from - $320 \mathrm{MPa}$ for $L_{1}=10 \mathrm{~m}$ to $+105 \mathrm{MPa}$ for $L_{1}=99 \mathrm{~m}$.

Fig. 5 shows that the back span length plays an important role in the structural behavior of both the deck and the pylon. Regardless of the pylon inclination, the smaller the $L_{1}$ the higher the sagging moments (and the corresponding deflections) in the deck. Similarly in the pylon, higher values of bending moments, especially at its bottom, and higher deflections, at its top, appear when $L_{1}$ decreases. The lack of symmetry of the bending moment diagram at the bottom of the pylon is a consequence of the lack of symmetry of the span distribution. This behavior is illustrated in the models with $\alpha=-20^{\circ}$, where the maximum sagging moments in the deck vary from $11 \mathrm{MNm}$ for $L_{1}=10 \mathrm{~m}$ to $6 \mathrm{MNm}$ for $L_{1}=99 \mathrm{~m}$, and in the pylon, these values vary from 42 $\mathrm{MNm}$ for $L_{1}=10 \mathrm{~m}$ to $21 \mathrm{MNm}$ for $L_{1}=99 \mathrm{~m}$.

\subsubsection{Study of the pylon inclination}

Fig. 6(A) shows that the pylon inclination defines the area of the stay cables according to the criterion presented in Section 3, where it was also established that the higher the stay inclinations the lesser efficient the stay and therefore, the higher the area required. As illustrated in Fig. 6(B), the pylon inclination also influences the oscillation of stresses in the stay cables, especially in those elements with the highest inclinations (located at the proximities of the abutment of the main span). In this stay cable, the minimum values of the stresses are increased when the pylon is inclined towards the back span $\left(\alpha<0^{\circ}\right)$ while the maximum ones are not significantly changed. For example, the minimum increment of stress in this stay varies from -50 MPa for $\alpha=-20^{\circ}$ to $130 \mathrm{MPa}$ for $\alpha=10^{\circ}$.

Fig. 6(C) shows that inclining the pylon towards the back span $\left(\alpha<0^{\circ}\right)$ results in slightly higher bending moment envelopes in the deck at the proximities of the pylon. For example, in the main span for $x=20 \mathrm{~m}$ the maximum hogging bending moment changes from $2 \mathrm{MNm}$ for $\alpha=10^{\circ}$ to $3 \mathrm{MNm}$ for $\alpha=-20^{\circ}$. The opposite happens when the pylon is inclined towards the main span $(\alpha$ $>0^{\circ}$ ). For example, in the main span for $x=80 \mathrm{~m}$ the maximum hogging bending moment changes from $5 \mathrm{MNm}$ in $\alpha=-20^{\circ}$ to $7 \mathrm{MNm}$ in $\alpha=10^{\circ}$.

It is noteworthy that when $\alpha<0^{\circ}$, the required area for the backstay is smaller because of the favorable weight of the pylon. Since this stay is not very efficient due to its small area, higher horizontal deflections in the pylon are obtained than in a structure where $\alpha>0^{\circ}$. This is appreciable in Fig. 6(E), where the maximum pylon deflections vary from $125 \mathrm{~mm}$ for $\alpha=10^{\circ}$ to $100 \mathrm{~mm}$ for $\alpha=-20^{\circ}$.

\subsubsection{Study of the pylon stiffness}

Since the cable areas are obtained only by considering its geometry and tributary length, the pylon stiffness does not influence them at all, as shown in Fig. 7(A). The increment of cable stresses is therefore only due to the pylon stiffness, and it is virtually negligible, as illustrated in Fig. 7(B). In the case of the deck bending moment envelopes presented in Fig. 7(C) slight 
differences appear at the proximities of both abutments. These differences are clearly observed when the envelopes of deflections in the deck of Fig. 7(D) are analyzed. As expected, higher envelopes of deflection are obtained in structures with flexible pylons. This figure also shows the importance of the back span length $\left(L_{1}\right)$. In highly asymmetrical structures (short $L_{1}$ ) the differences between both envelopes are limited to positive deflections in the main span while in the more symmetrical structures (high $L_{1}$ ) these differences appear in both positive and negative deflections. As illustrated in Fig. 7(F), the stiffness is a factor of major importance in the structural response of the pylon. In fact, this figure shows that main differences between the models with stiff and flexible pylons are obtained at intermediate heights. The differences of deflections at the deck are a consequence of the sensitivity of flexible pylons to horizontal loads. These differences are found in both the positive and the negative pylon deflections in structures with high $L_{1}$ and limited to the positive deflections in structures with small $L_{1}$.

\subsubsection{Study of the deck stiffness}

For the same reason that in the previous study, the deck stiffness does not affect the definition of the cable areas, as shown in Fig. 8(A). In Fig. 8(B) it is presented that the deck stiffness does not play an important role in the stay stresses. Regarding the bending moment envelopes in the deck presented in Fig. 8(C) slight differences appear at the proximities of abutments (hogging moments in the main span abutment and sagging moments in the back span one). As presented in Fig. 8(D), the higher the deck stiffness the lower the deck deflections. However, the reduction of the deck deflections is not proportional to the increase of the deck stiffness. It seems, as happens with symmetrical bridges, that increasing the deck stiffness is not the most efficient way to reduce its deflections. Similar behavior is found at the pylon (Figs. 8(E) and (F)), as both bending moments and deflections increase with the deck stiffness.

\subsubsection{Study of the backstay stiffness}

Fig. 9 shows the benefits, in both the deck and the pylon, of increasing the stiffness of the backstay. As presented in Section 4.5.1, the backstay area strictly obtained corresponds to $\gamma_{B S}=1$. For example, maximum hogging moments in the deck are reduced from $3 \mathrm{MNm}$ for $\gamma_{B S}=1$ to 2.5 $\mathrm{MNm}$ for $\gamma_{B S}=2$. Nevertheless, the favorable effect of stiffening the stay is successively less advantageous when $\gamma_{B S}$ is increased. In fact, the maximum hogging moments in the deck only change from 2.2 MNm for $\gamma_{B S}=5$ to $2.1 \mathrm{MNm}$ for $\gamma_{B S}=10$. However, as illustrated in Fig. 9(C), the backstay stiffness is a design parameter that can be efficiently used to reduce the pylon deflections.

\subsubsection{Study of the stay configuration}

Since the angle of the cables is the same for each span in bridges with harp configuration, the areas of the cables in the same span are equal (Fig. 10(A)). As presented in Fig 10(B), main increment of cable stresses are found at the vicinities of the pylon. Figs. 10(E) and (F) show how, in bridges with semi-fan configuration, the need for additional intermediate supports at the backstay span is evident. This fact is illustrated by the high deflections at intermediate zones of the pylon. As a consequence of the lack of additional fixed points, the deck deflections for harp configuration are also very high (Fig. 10(D)). Regarding this point, there is not significant variation with respect to symmetrical bridges.

\subsubsection{Study of the geometrical nonlinearity}

Fig. 11 shows that the effect of geometrical nonlinearity is very small and its consideration does 
not affect the previously described responses.

\subsection{Discussion}

\subsubsection{Initial design of the cable areas}

A primary criterion to define the cable area consists of limiting its maximum stress to a percentage of the cable strength (usually the $45 \%$, see Svensson 2012) assuming a tributary area in the deck for both permanent and live loads. A second criterion defines the cable areas limiting the oscillation of axial stresses to $200 \mathrm{MPa}$ when a given percentage of the live loads is applied (in this paper this percentage has been assumed as $100 \%$ ).

In the simulations presented in this paper, only distributed live loads, and not heavy vehicles are considered. As presented in Figs. 4(B) and 5(B), these assumptions are on the unsafety side, since when heavy vehicles are not considered the area of the cables are underestimated. For these reasons, when only distributed loads are considered, it seems reasonably to reduce the percentage of the cable strength from $45 \%$ to $35 \%$ or a similar value. On the other hand, the oscillation of stay stresses criterion might be the determining criterion in light cable-stayed bridges. In these structures, the ratio of the live load considered in the oscillation is defined by the structural code. This ratio is usually lower than the $100 \%$ assumed in the presented analyses.

\subsubsection{Design of the backstays}

Fig. 12(A) shows the area of the backstays in structures with different pylon inclinations $(\alpha=-$ $20^{\circ},-10^{\circ}, 0^{\circ}, 10^{\circ}$ and $20^{\circ}$ ) for a back span length $L_{2}$ ranging from 10 to $100 \mathrm{~m}$. The geometries and mechanical properties of these models are defined according to the procedures presented in Sections 1 and 3, respectively.

This figure shows: (1) Role of the pylon inclination: The higher the pylon inclination towards the main span $\left(\alpha<0^{\circ}\right)$, the higher the backstay area as this element has also to resist the unfavorable weight of the pylon. The opposite effect appears when the pylon is inclined towards the back span $\left(\alpha>0^{\circ}\right)$. (2) Role of the back span length: Independently of the pylon inclination, a minimal backstay area is obtained when the back span length represents a ratio between the 20 and $50 \%$ of the main span length.

\subsubsection{Axial forces and stresses in the backstays}

The axial force for permanent loads in the backstay has been defined to set to zero the bending moments at the pylon foundation. In a symmetrical bridge $\left(L_{1} / L_{2}=1\right)$ the axial force in the backstay is very low. As $L_{1} / L_{2}$ reduces, the axial force of the backstay for permanent loads increases. This force also depends on the pylon inclination. In fact, when $\alpha>0^{\circ}$, the backstay force is reduced because of the favorable effect of the pylon weight.

The axial force in the backstays oscillates due to the live loads. This is appreciable in Fig. 12(B), where the variation of axial forces in the backstays of structures with two pylon inclinations $\left(\alpha=-0^{\circ}\right.$ and $\left.10^{\circ}\right)$ and different back span lengths $\left(L_{2}\right.$ from 10 to $\left.100 \mathrm{~m}\right)$ are compared. This figure shows the axial forces due to permanent loads, and their maximum and minimum axial forces, when, besides, live loads act upon the bridge. This figure shows that in structures with a reduced length $L_{2}$ the axial forces for permanent loads are practically equal to the minimum ones. On the other hand, when $L_{2}$ is near $L_{1}$, the axial forces for permanent loads present a medium value between the maximum and the minimum lines. This situation can be easily explained by the fact that the live loads in the back span reduce the tensile stresses of the backstay, while the live loads 

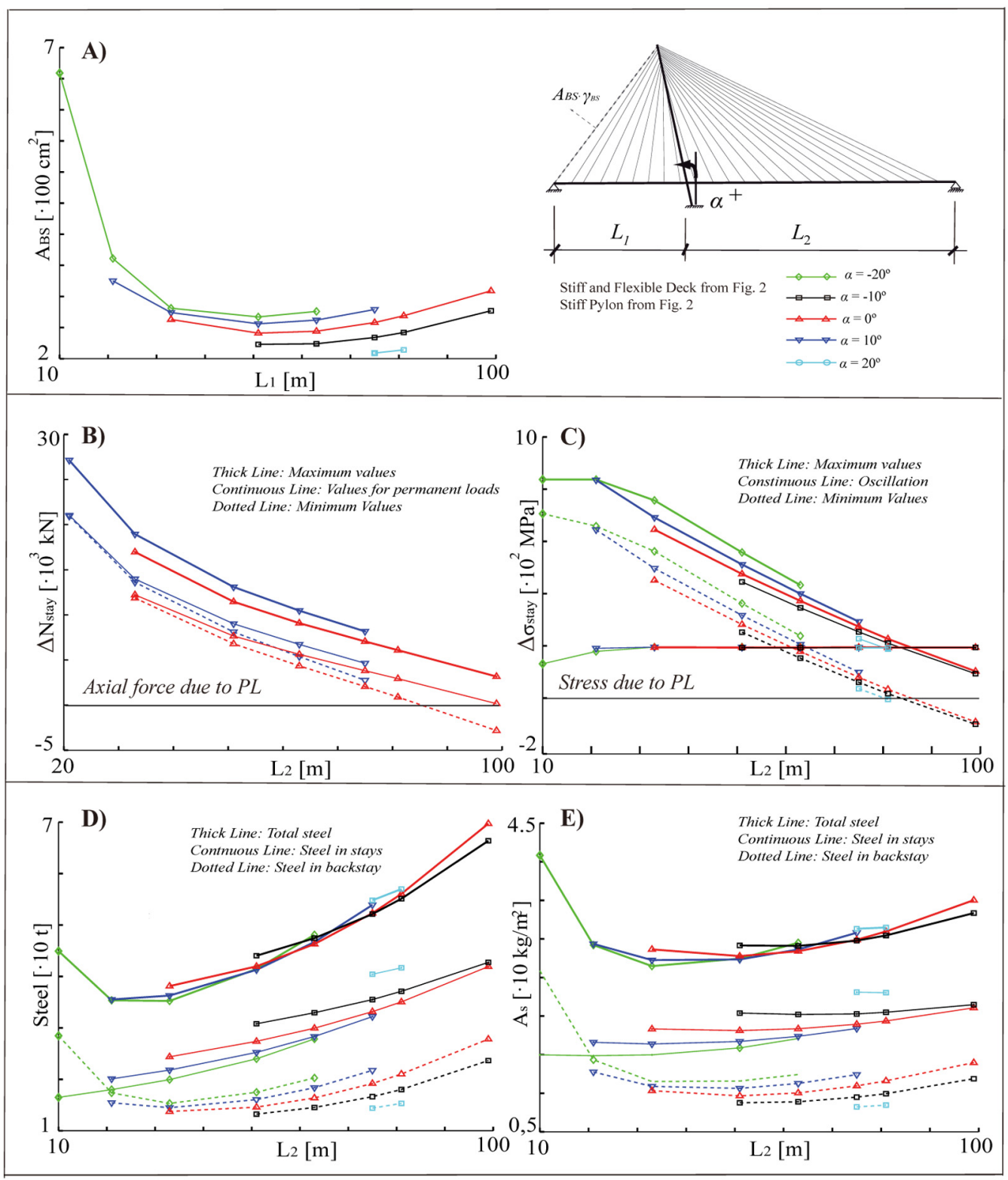

Fig. 12 Results backstay areas (A); variation of stay forces due to live loads (B); variation of stay stresses due to live loads (C); steel consumption (D); and steel in $\mathrm{kg} / \mathrm{m}^{2}$ (E)

in the main span present the opposite effect.

In the vast majority of bridges analyzed, the stress oscillation criterion has been the most adverse criterion to define the backstay area. This is appreciable in Fig. 12(C), where the increments of axial stresses in the backstays of structures with two pylon inclinations $\left(\alpha=0^{\circ}\right.$ and $10^{\circ}$ ) and different back span lengths ( $L_{2}$ from 10 to $100 \mathrm{~m}$ ) are compared, and where the maximum and minimum of their stresses and their oscillation are shown. Fig. 12(C) shows that in most of the structures the stress oscillations in stays are near to $200 \mathrm{MPa}$ (design threshold assumed in the codes). 


\subsubsection{Weight of steel in cables}

The weights of steel in cables in cable-stayed bridges with five pylon inclinations $\left(\alpha=-20^{\circ}\right.$, $10^{\circ}, 0^{\circ}, 10^{\circ}$ and $20^{\circ}$ ) and different back span lengths ( $L_{2}$ from 10 to $100 \mathrm{~m}$ ) are summarized in Fig. 12(D), where the weight of the backstay cables, the rest of the cables and of all the cables are compared. Fig. 12(D) can be expressed in terms of $\mathrm{kg} / \mathrm{m}^{2}$ as presented in Fig. 12(E). In this figure the minimum steel weight is obtained when $L_{2}$ is near $40 \mathrm{~m}\left(L_{2} / L_{1}=0.40\right)$.

For all the pylon inclinations the minimum value is obtained for $\alpha=-20^{\circ}$, although the differences are not significant. In symmetrical bridges the optimal pylon inclination is $\alpha=10^{\circ}$. On the other hand, when $0.55 \leq L_{2} / L_{1} \leq 0.75$ the optimal pylon corresponds with $\alpha=0^{\circ}$. It is remarked that differences between the different cases are not significant enough to advice one or another pylon inclination. This is not the case in structures with a short $L_{2}$ span as in this structures the steel weight is significantly reduced when $\alpha<0^{\circ}$.

\subsubsection{Deflections limits}

An important aspect to take into account is the fact that no deflection limitations are introduced in Fig. 12(D) and 12(E). A reference value might be considered as $L_{2} / 1000$ for the frequent live load (IAP 11), which corresponds to the Load Model $4\left(5 \mathrm{kN} / \mathrm{m}^{2}\right)$ defined at Eurocode 0 , factored by $\psi$ $=0,4$. Nevertheless, this ratio might be reduced in agreement with the client. For example, in the Sunniberg Bridge this value was as low as $L_{2} / 400$ (Marchetti and Lecinq 1999).

\subsubsection{Effect of the backspan length}

The back span length plays an important role in the structural response of the bridge. The shorter this length, the higher both the bending moments and the deflections in the main span. In very short back spans, the pylon only leans towards the main span and the bending moments due to live loads use to have a predominant sign.

The tensile forces in the cables are usually concentrated at the places with maximum hogging moments and are reduced significantly at the proximities of the abutments. In the proximities of the pylon, the maximum stresses do not vary significantly between adjacent stays.

\subsubsection{Effect of the pylon inclination}

When the pylon lends towards the back span for a certain back span length, both the bending moments and the deflections of the main span slightly increase. The bending moments in the pylon are practically the same but the maximum values are located at different heights. It is to be remarked that the pylons leaning towards the back span present higher horizontal deflections.

\subsubsection{Effect of the deck stiffness}

The analyzed structures show that increasing the deck stiffness is not recommendable as the bending moments and deflections are not reduced in the same proportion. For example, when the deck inertia is increased 11.35 times (that is to say, when the deck is changed from flexible to stiff) the maximum bending moments and deflections in this element are only reduced the $3,84 \%$ and the $9,72 \%$, respectively.

\subsubsection{Effect of the pylon-back stay stiffness}

Vertical deflections at the deck are counteracted by two complementary structural systems: the axial stiffness of the backstay and the bending stiffness of the pylon. Increasing the backstay stiffness is a much more efficient way to reduce the deflections and internal forces at the deck. 


\subsubsection{Effect of the stay configuration}

The bending moments in both spans are higher for the harp configuration than for the semi-fan one.

As expected, major differences appear in the pylon when the two configurations are compared. As the harp configuration is more sensitive to horizontal loads, higher horizontal deflections throughout the pylon are obtained. These horizontal deflections increase the vertical deflections in the deck. From the results obtained it might be concluded that the harp system is less efficient than the semi-fan one. To increase the efficiency of the harp system intermediate supports can be introduced to anchor the deck (as in the Knie Bridge).

\subsubsection{Effect of the geometrical nonlinearity}

For the cases studied, the effect of the geometrical nonlinearity is not significant.

\section{Conclusions}

This paper presents a parametric study addressing the structural response of asymmetrical cable-stayed bridges. In this analysis, the effects of the main design parameters (the pylon inclination, the back span length, the stiffness of the deck, pylon and backstay and the stay configuration) are compared. This study includes the role of the geometrical nonlinearity. Despite of the growing number of built examples, this structural type has deserved little attention from researchers.

The parametric analyses carried out show that: (1) In the vast majority of analyzed bridges, the stress oscillation criterion stands as the most adverse criterion to define the backstay area. On the contrary, the rest of the stays are usually defined by limiting its axial strength. (2) The higher the pylon inclination towards the main span, the higher the backstay area. The minimal backstay area is obtained when the back span length represents a ratio between the 20 and $50 \%$ of the main span length. (3) In most analyzed structures, variations in steel weight between structures with different pylon inclinations are not significant enough. Nevertheless, this is not the case in structures with a short backspan. In these structures, the steel weight is significantly reduced when the pylon is lent towards the backspan. (4) The backspan length plays an important role in the structural response of asymmetrical bridges. The shorter this length, the worse the structural response in the main span is. (5) Leaning the pylon towards the back span for a certain back span length, worsen the structural behavior of the main span. (6) Deck deflections are not reduced in the same proportion when the deck bending stiffness is increased. For this reason, the use of stiffer decks is not advised. (7) Increasing the backstay stiffness is more efficient to improve the deck behavior than increasing the bending stiffness of the pylon. (8) Generally speaking, the harp configuration is less efficient than the semi-fan one. (9) The geometrical nonlinearity does not play an important role in the structural response of the asymmetrical bridges analyzed in this study.

As a final conclusion, generally speaking, asymmetrical bridges present a less efficient structural behavior, since the disadvantages of symmetrical bridges are enhanced, especially for very short back spans. As showed above, factors like the area and inclination of the backstay cable, the cable arrangement (harp or semi-fan), the stiffness and inclination of the pylon, and the stiffness of the deck, are of major importance. With no doubts, this kind of bridges need further studies in order to, for example, establishing criteria to design the area of the backstay cables. These and other problems will be addressed in the near future by the authors. 


\section{Acknowledgments}

The authors would like to thank the former students D. Javier Sánchez Mateos Enrique, D. Mario Pérez Sánchez and D. Alberto de la Torre Palencia for contributing to the initial studies of this paper. The authors thank the Spanish Ministerio de Economia y Competitividad and the FEDER funds for the funding provided through the research grant BIA2013-47290-R.

\section{References}

Agrawal, T.P. (1997), “Cable-stayed bridges-parametric study”, J. Bridge Eng., 2(2), 61-67.

Atmaca, B. and Ates, S. (2012), "Construction stage analysis of three-dimensional cable-stayed bridges", Steel Compos. Struct., Int. J., 12(5), 413-426.

Baldomir, A., Hernandez, S., Nieto, F. and Jurado, A. (2010), "Cable optimization of a Long Span CableStayed Bridge in la Coruna (Spain)", J. Adv. Eng. Software, 41(7-8), 931-938.

Bazant, Z.P. (1972), "Prediction of concrete creep effects using age-adjusted effective modulus method", ACI Journal, 69(20), 212-217.

Casas, J.R. and Aparicio, A.C. (1998), "Monitoring of the Alamillo cable-stayed bridge during construction", Experim. Mech., 38(1), 24-28.

Chen, D.W., Au, F.T.K., Tham, L.G. and Lee, P.K.K. (2000), "Determination of initial cable forces in prestressed concrete cable-stayed bridge for given design deck profiles using the force equilibrium method", Comput. Struct., 74(1), 1-9.

Du, G.H. (1989), "Optimal cable tension and construction tensioning of cable-stayed bridges", Bridge Construct., 74, 18-22. [In Chinese]

Eurocode 3 (2005), Design of Steel Structures.

Gimsing, N.J. (1997), Cable Supported Bridges, Concept and Design, John Wiley and Sons, Chichester, UK.

Guan, H. (2000), "Construction control of cable-stayed bridges”, Ph.D. Thesis; The Hong Kong University of Science and Technology, Hong Kong, China.

Gunaydin, M., Adanur, S., Altunisik, A.C., Sevim, B. and Turker, E. (2014), "Determination of structural behavior of Bosporus suspension bridge considering construction stages and different soil conditions", Steel Compos. Struct., Int. J., 17(4), 405-429.

Hassan, M.M. (2013), "Optimization of stay cables in cable-stayed bridges using Finite element, genetic algorithm, and b-spline combined technique", Eng. Struct., 49, 643-654.

Hassan, M.M., Nassef, A.O. and El Damatty, A.A (2012), "Determination of optimum post-tensioning cable forces of cable-stayed bridges", Eng. Struct., 44, 248-259.

Janjic, D., Pircher, M. and Pircher, H. (2002), "The unit load method - some recent applications", Adv. Steel Struct., II, 831-837.

Janjic, D., Pircher, M. and Pircher, H. (2003), "Optimization of cable tensioning in cable-stayed bridges", $J$. Bridge Eng., 8(3), 131-137.

Jorquera-Lucerga, J.J. (2013), “Understanding Calatrava's bridges: A conceptual approach to the 'La Devesa-type' footbridges”, Eng. Struct., 56, 2083-2097.

Lazar, B.E., Troitsky, M.S. and Douglas, M.C. (1972), "Load analysis balancing of cable-stayed bridges", ASCE J. Struct. Eng., 92(8), 1725-1740.

Lozano-Galant, J.A., Paya-Zaforteza, I., Xu, D. and Turmo, J. (2012a), “Analysis of the construction process of cable-stayed bridges built on temporary supports”, Eng. Struct., 40, 95-106.

Lozano-Galant, J.A., Paya-Zaforteza, I., Xu, D. and Turmo, J. (2012b), "Forward Algorithm for the construction control of cable-stayed bridges built on temporary supports", Eng. Struct., 40, 119-130.

Lozano-Galant, J.A., Xu, D., Paya-Zaforteza, I. and Turmo, J. (2013), "Direct simulation of the tensioning process of cable-stayed bridges", Comput. Struct., 121, 64-75.

Lozano-Galant, J.A. and Turmo, J. (2014a), “An algorithm for simulation of concrete cable-stayed bridges 
built on temporary supports and considering time dependent effects”, Eng. Struct., 79, 341-353.

Lozano-Galant, J.A. and Turmo, J. (2014b), "Creep and shrinkage effects in service stresses of concrete cable-stayed bridges", Comput. Concrete, 13(4), 483-499.

Lozano-Galant, J.A., Ruiz-Ripoll, L., Paya-Zaforteza, I. and Turmo, J. (2014), "Modifications of the stressstate of cable-stayed bridges due to staggered erection of their superstructure", The Baltic J. Road Bridge Eng., 9(4), 241-250.

Lozano-Galant, J.A., Paya-Zaforteza, I. and Turmo, J. (2015), "Effects in service of the staggered construction of cable-stayed bridges built on temporary supports", The Baltic J. Road Bridge Eng., 10(3), 247-254.

Lute, V., Upadhyay, A. and Singh, K.K. (2009), "Computationally efficient analysis of cable-stayed bridge for GA-based optimization”, Eng. Appl. Artif. Intel., 22(4-5), 750-758.

Manterola, J., Siegrist, C. and Gil, M.A. (2006), Puentes, Escuela Técnica Superior de Ingenieros de Caminos, Canales y Puertos de Madrid, Madrid, Spain. [In Spanish]

Marchetti, M. and Lecinq, B. (1999), "Stay adjustment: From design perspective to on site practice", Proceedings of IABSE, Malmö, Sweden, June.

Menn, C. (1990), Prestressed Concrete Bridges, Springer Science \& Business Media.

Negrao, J.H.O. and Simoes, L.M.C. (1997), "Optimization of cable-stayed bridges with three dimensional modeling", Comput. Struct., 64(1-4), 741-758.

Scotti, A. (2003), "Long term behavior of cable-stayed bridges", Master's Thesis; Polititecnico di Milano, Italy.

SETRA (2001), Recommandations de la Commission Interministrielle de la Precontrainte, Service d'Etudes Techniques des Routes et Autoroutes, France.

Simoes, L.M.C. and Negra, J.H.J.O. (2000), "Optimization of cable-stayed bridges with box-girder decks", Adv. Eng. Software, 31(6), 417-423.

Svensson, H. (2012), Cable-Stayed Bridges: 40 years of Experience Worldwide, Wiley.

Virlogeux, M. (1994), "Erection of cable-stayed bridges: the control of the designed geometry", Proceedings of International Conference A.I.P.C., F.I.P., Cable-Stayed and Suspension Bridges, Volume 2, Deauville, France, October, pp. 321-350.

Walther, R., Houriet, B., Isler, W., Moïa, P. and Klein, J.F. (1999), Cable-Stayed Bridges, Thomas Telford.

Wang, P.H., Tseng, T.C. and Yang, C.G. (1993), "Initial shape of cable-stayed bridges", Comput. Struct., 46(6), 1095-1106.

Wang, Y.C., Vlahinos, A.S. and Shu, H.S. (1997), “Optimization of cable preloading on cable-stayed bridges", SPIE, 3043, 248-259.

CC 